\title{
Sensor-augmented pump therapy from the diagnosis of childhood type 1 diabetes: results of the Paediatric Onset Study (ONSET) after 12 months of treatment
}

\author{
O. Kordonouri • E. Pankowska • B. Rami • T. Kapellen • \\ R. Coutant • R. Hartmann • K. Lange • M. Knip • \\ T. Danne
}

Received: 15 April 2010 / Accepted: 15 July 2010 /Published online: 14 August 2010

(C) Springer-Verlag 2010

\begin{abstract}
Aims/hypothesis The value of managing children with type 1 diabetes using a combination of insulin pump and continuous glucose monitoring starting from diagnosis for improving subsequent glycaemic control and preserving residual beta cell function was determined.

Methods A total of 160 children (aged 1-16 years, mean \pm SD: $8.7 \pm 4.4$ years; $47.5 \%$ girls) were randomised to receive insulin pump treatment with continuous glucose monitoring or conventional self-monitoring blood glucose measurements. The primary outcome was the level of $\mathrm{HbA}_{1 \mathrm{c}}$ after 12 months. Other analyses included fasting
\end{abstract}

Electronic supplementary material The online version of this article (doi:10.1007/s00125-010-1878-6) contains supplementary material, which is available to authorised users.

O. Kordonouri $\cdot$ R. Hartmann · T. Danne $(\bowtie)$

Bult Diabetes Centre for Children and Adolescents,

Kinderkrankenhaus auf der Bult,

Janusz-Korczak-Allee 12,

D-30173 Hannover, Germany

e-mail: danne@hka.de

E. Pankowska

Department of Paediatric Diabetology and Birth Defects,

Medical University of Warsaw,

Warsaw, Poland

B. Rami

Department of Paediatrics, Medical University of Vienna,

Vienna, Austria

T. Kapellen

Universitätsklinik und Poliklinik für Kinder und Jugendliche,

Leipzig, Germany
C-peptide, glycaemic variability, sensor usage, adverse events, children's health-related quality of life and parent's wellbeing.

Results $\mathrm{HbA}_{1 \mathrm{c}}$ was not significantly different between the two groups, but patients with regular sensor use had lower values (mean $7.1 \%, 95 \%$ CI $6.8-7.4 \%$ ) compared with the combined group with no or low sensor usage (mean $7.6 \%$, $95 \%$ CI $7.3-7.9 \% ; p=0.032)$. At 12 months, glycaemic variability was lower in the sensor group (mean amplitude of glycaemic excursions $80.2 \pm 26.2$ vs $92.0 \pm 33.7$; $p=0.037)$. Higher $\mathrm{C}$-peptide concentrations were seen in sensor-treated 12 - to 16 -year-old patients $(0.25 \pm 0.12 \mathrm{nmol} / \mathrm{l})$

R. Coutant

Département de Pédiatrie, Centre Hospitalier Universitaire,

Angers, France

K. Lange

Department of Medical Psychology, Hannover Medical School, Hannover, Germany

M. Knip

Hospital for Children and Adolescents and Folkhälsan Research Centre, University of Helsinki,

Helsinki, Finland

M. Knip

Department of Paediatrics, Tampere University Hospital,

Tampere, Finland 
compared with those treated with insulin pump alone $(0.19 \pm 0.07 \mathrm{nmol} / 1 ; p=0.033)$. Severe hypoglycaemia was reported only in the group without sensors (four episodes). Conclusion/interpretation Sensor-augmented pump therapy starting from the diagnosis of type 1 diabetes can be associated with less decline in fasting C-peptide particularly in older children, although regular sensor use is a prerequisite for improved glycaemic control.

\section{Trial registration ISRCTN.org ISRCTN05450731}

Funding Medtronic International Trading Sàrl, Tolochenaz, Switzerland

Keywords Continuous glucose monitoring $\cdot \mathrm{C}$-peptide . Glycaemic variability $\cdot \mathrm{HbA}_{1 \mathrm{c}} \cdot$ Quality of life .

Sensor-augmented pump therapy · Severe hypoglycaemia

$\begin{array}{ll}\text { Abbreviations } \\ \text { CGM } & \text { Continuous glucose monitoring } \\ \text { CSII } & \text { Continuous subcutaneous insulin infusion } \\ \text { MAGE } & \text { Mean amplitude of glycaemic excursions } \\ \text { SMBG } & \text { Self-monitoring of blood glucose }\end{array}$

\section{Introduction}

Intensive insulin therapy is important in avoiding diabetesrelated microvascular and macrovascular complications [1], but may also have a role in preserving residual beta cell function [2]. Levels of C-peptide are now being increasingly recognised as a primary endpoint in intervention trials in patients with newly diagnosed type 1 diabetes [3]. High number of blood glucose tests per day was shown to be the most important factor related to an improved $\mathrm{HbA}_{1 \mathrm{c}}$ level in adolescents [4]. In short-term studies, the use of continuous glucose monitoring (CGM) has been shown to improve glycaemic control and variability, both in children and in adults with long-standing type 1 diabetes $[5,6]$, whereas in a long-term study lasting 26 weeks, a beneficial effect of CGM was seen only in adults [7]. Despite problems that may be related to the inconvenience of wearing CGM devices, low compliance and consequently poor glycaemic results, particularly in young patients, may be associated with difficulties in implementing the information from the system and adjusting the therapy accordingly. Integrating CGM into the diabetes treatment from the onset of clinical disease could lead to a better understanding of the individual interplay between exogenous insulin requirements, prandial glycaemic excursions and sport activities, and so, may imprint the patient's treatment approach in the long term.

Therefore, we performed a multicentre randomised controlled trial to assess the acceptance, efficacy and safety of the use of CGM in combination with insulin pump therapy from the diagnosis of type 1 diabetes in children and adolescents. Particularly, we set out to determine whether the use of sensor-augmented insulin pump therapy leads to better glycaemic control, lower daily insulin requirements, higher residual beta cell function, lower incidence of severe hypoglycaemia and better quality of life after 1 year of treatment compared with the use of a conventional insulin pump combined with conventional self-monitoring of blood glucose.

\section{Research design and methods}

Patients Children and adolescents between 1 and 16 years of age with a diagnosis of type 1 diabetes within 4 weeks before study entry were eligible for inclusion. Patients were treated in five European paediatric centres experienced in insulin pump treatment and CGM use (Hannover and Leipzig, Germany; Vienna, Austria; Warsaw, Poland; Angers, France). A minimum of ten patients per centre was required. The study was approved by the Ethical Committee of each participating centre. Written informed consent was obtained from patients and their parents or guardians.

Patients were assigned by a central randomisation procedure to receive either sensor-augmented insulin pumps (Paradigm REAL-Time Insulin Pump and Continuous Glucose Monitoring System, Medtronic MiniMed, Northridge, CA, USA) or MiniMed Paradigm 515/715 insulin pumps (Medtronic MiniMed) and blood glucose meters.

Patients were instructed to use the CGM device on a daily basis, replace the sensors every 3 days and to confirm glucose measurements by self-monitoring of blood glucose (SMBG) before making management decisions, as required from the labelling on the regulatory device. Patients in the control group were given blood glucose meters and asked to perform SMBG at least four times a day. Glycaemic targets were identical in all study centres and corresponded to those suggested by the International Society of Paediatric and Adolescent Diabetes [8] with optimal target pre-meal glucose values between 5.0 and $8.0 \mathrm{mmol} / \mathrm{l}$, peak postprandial values below $10.0 \mathrm{mmol} / \mathrm{l}$, bedtime values between 6.7 and $10.0 \mathrm{mmol} / \mathrm{l}$ and overnight values between 4.5 and $9.0 \mathrm{mmol} / \mathrm{l}$.

Follow-up Study visits were conducted at baseline and at 6,26 and 52 weeks ( \pm 1 week) thereafter. Patients of both arms received the same local standard care as given to the off-study patients of each centre including phone contact in case of acute complications and routine diabetes management visits at the diabetes outpatient clinic, occurring regularly every $6-10$ weeks. Before the study visits at 6 and 52 weeks, the control group used a 
blinded continuous glucose monitor (Guardian REALTime Clinical device, Medtronic MiniMed) for 6 days. At each visit, the insulin pump data were downloaded in a blinded fashion using the web-based application CareLink Clinical (Medtronic MiniMed). Variables (dose of insulin per day, percentages of basal and bolus insulin dose as well as average number of daily boluses) and sensor data (glucose average and variability, i.e. glucose SD and mean amplitude of glycaemic excursions [MAGE]) [9] were calculated on a $24 \mathrm{~h}$ basis. At baseline and at 52 weeks, C-peptide levels were determined in fasting conditions. At the start of the study and at 24 and 52 weeks, children aged 8-18 years and the primary caregiver were asked to complete the DISABKIDS [10] and KIDSCREEN-27 [11, 12] questionnaires to evaluate patient's health-related quality of life and caregiver's impression of patient's quality of life and own wellbeing assessed by the WHO-5 questionnaire [13].

Laboratory assessment $\mathrm{HbA}_{1 \mathrm{c}}$ was measured centrally at baseline as well as at every study visit using HPLC (BioRad Laboratories, Munich, Germany; LKF-Laboratorium für Klinische Forschung, Kiel, Germany). Diabetesassociated autoantibodies (islet cell antibodies [ICA]; insulin autoantibodies [IAA]; glutamic acid decarboxylase antibodies [GADA]; tyrosine phosphatase-related islet antigen-2 antibodies [IA-2A]; zinc transporter 8 antibodies [ZnT8A]) at diagnosis of diabetes were analysed centrally using in-house methods by the Scientific Laboratory, Hospital for Children and Adolescents, University of Helsinki, Finland. In the IAA assay, mono-125I (TyrA14) human recombinant insulin (GE Healthcare, Chalfont St Giles, UK; activity $7,400 \times 10^{10} \mathrm{~Bq} / \mathrm{mmol}$ ) was used as the labelled antigen and in the GADA, IA-2A and ZnT8A assays antigens produced in house through in vitro transcription and translation were used. Fasting C-peptide and plasma glucose concentrations were analysed in the LKF-laboratory using the Immuno-Analyzer Centaur Advia System and the hexokinase method, respectively. All laboratory results were blinded to the investigators.

Statistical analysis Sample size estimate was based on the primary outcome variable ( $\mathrm{HbA}_{1 \mathrm{c}}$ after 12 months) and a previous analysis of paediatric patients with an estimated average of $\mathrm{HbA}_{1 \mathrm{c}}$ of $8.0 \%$ (SD $1.0 \%$ ) after 1 year of type 1 diabetes (O. Kordonouri and T. Danne, unpublished data). The hypothesis of the current study was to detect an $\mathrm{HbA}_{1 \mathrm{c}}$ difference of $0.5 \%$ comparing the two treatment groups at the end of the treatment phase using a two-sample $t$ test with two-sided alpha of 0.05 . A total sample size of 160 randomised patients with equal numbers in each group was planned to achieve a statistical power of $80 \%$ and reach an evaluable dataset of 64 patients per group, allowing for a $20 \%$ dropout rate. The statistical evaluation was performed by intention-to-treat analysis according to treatment groups defined as randomised using the statistical software package SPSS 12.0. Standard procedures were used such as Fisher's $\chi^{2}$ test, $t$ test and nonparametric Mann-Whitney $U$ test or Wilcoxon test when appropriate. The association between rank-ordered variables was assessed by Spearman correlation coefficient $(\rho)$. The Kaplan-Meier method with the logrank test was used to analyse and compare $\mathrm{HbA}_{1 \mathrm{c}}$ between the study groups in relation to sensor use. A statistically significant difference was assumed with a twosided level of $p<0.05$ for each test.

\section{Results}

Patients Between February 2007 and October 2008, 357 eligible children and adolescents were diagnosed with type 1 diabetes in the five participating centres (Table 1). Study participation was offered to 295 patients. A total of 160 patients agreed to take part in the study and were randomised on average $9.6 \pm 6.0$ days (mean $\pm \mathrm{SD}$ ) after diagnosis, with 80 patients assigned to each of the two randomisation groups (acceptance rate 54.2\%). Only 154 patients completed all visits and were evaluable for statistical analyses (sensor-augmented pump vs pump alone: 76 vs 78 , dropout rate $3.8 \%$ ). Clinical and biochemical characteristics at baseline did not differ between the treatment groups (Table 2).

Glycaemic control and variability $\mathrm{HbA}_{1 \mathrm{c}}$ of both treatment groups was not significantly different throughout the total period. At each follow-up visit, $\mathrm{HbA}_{1 \mathrm{c}}$ levels in patients with sensor-augmented pump therapy were persistently below those of patients treated with insulin pump and SMBG (Table 3). $\mathrm{HbA}_{1 \mathrm{c}}$ at 12 months was $7.5 \pm 1.1 \%$ in the total cohort. No significant differences between treatment groups were seen within the age groups. In total, 30 out of 76 patients $(39.5 \%)$ with sensor-augmented pump had $\mathrm{HbA}_{1 \mathrm{c}}$ levels below $7.0 \%$ at 12 months compared with 26 of 77 patients $(33.8 \%)$ with insulin pump alone $(p=0.464)$. At 12 months, the $24 \mathrm{~h}$ glucose average was comparable between the groups $(p=0.966)$, but glycaemic variability was lower in the sensor group and reached statistical significance for MAGE (Table 4).

Documented sensor use data over the whole study period were available for 55 patients. Patients with sensoraugmented insulin pump had an average of $1.4 \pm 0.7$ sensor uses per week. Sensor usage was significantly higher at 6 weeks $(2.1 \pm 0.9$ sensors per week $)$ and declined significantly at 26 weeks $(1.4 \pm 1.0$ sensors per week) and 52 weeks $(1.1 \pm 0.7$ sensors per week), respectively $(p<0.001)$. There were no significant differences between the age groups in the frequency of sensor use $(p=0.497)$. 
Table 1 Study cohort flowchart

\begin{tabular}{ll} 
Characteristic & Number of patients \\
\hline $\begin{array}{l}\text { Eligible patients with onset of type 1 } \\
\text { diabetes aged 1-16 years }\end{array}$ & 357 \\
Not meeting inclusion criteria & 62 \\
Study offered to patients/parents & 295 \\
Refused to participate & 135 \\
Patients/parents consent, enrolled, and & 160 \\
$\quad$ randomised & \\
Overall recruitment rate & $44.8 \%$ \\
Random allocation: sensor-augmented & $80 / 80$ \\
pump/pump alone & \\
Follow-up: discontinued due to patient & $4 / 2$ \\
$\quad$ or parent refusal & \\
Evaluation: patients analysed & (dropout excluded)
\end{tabular}

Patients with regular sensor use (at least one sensor per week during the first year) had significantly lower $\mathrm{HbA}_{1 \mathrm{c}}$ (mean 7.1\%, 95\% CI 6.8-7.4\%) compared with the combined group of patients with no or low sensor usage, i.e. less than 1 sensor per week $(7.6 \%, 95 \%$ CI $7.3-7.9 \%$; $p=0.032$ ) (Fig. 1). Nineteen of 37 (51.4\%) patients with regular sensor use had $\mathrm{HbA}_{1 \mathrm{c}}$ below $7.0 \%$ at 12 months. There was a significant inverse correlation between $\mathrm{HbA}_{1 \mathrm{c}}$ and frequency of sensor usage at the 6 week visit ( $\rho=-0.268, p=0.026$ ), but no such relationship was seen at the 26 week $(\rho=0.009, p=0.942)$ or 52 week visit ( $\rho=-0.066, p=0.615)$. Patients with sensor-augmented insulin pumps performed fewer self-monitoring blood glucose finger sticks per day $(5.2 \pm 2.0)$ than those with insulin pump alone $(6.5 \pm 2.1, p<0.001)$.

Insulin requirements and endogenous insulin secretion Insulin requirements did not differ significantly between the groups during the study. At 12 months, the total daily insulin dose was $0.59 \pm 0.22 \mathrm{U} / \mathrm{kg}$ body weight in patients with sensor-augmented insulin pump and $0.64 \pm 0.23 \mathrm{U} / \mathrm{kg}$ body weight in those with insulin pump only $(p=0.248)$. The proportion of basal insulin was $29.7 \pm 10.4 \%$ in the control group, which was significantly lower than in the sensor-augmented pump group $(34.0 \pm 11.8 \%, p=0.021)$. In terms of the average number of daily boluses, patients in the sensor-augmented pump group injected $7.9 \pm 3.6$ boluses per day compared with $7.0 \pm 2.7$ in the control group $(p=0.097)$.

Fasting C-peptide concentration at baseline was not associated with $\mathrm{HbA}_{1 \mathrm{c}}(\rho=-0.099, r=0.225)$ and did not significantly differ between the groups (Table 2). In the total cohort, we observed a slight decrease in basal Cpeptide secretion over the first year (Table 3). The

Table 2 Patient characteristics at baseline

\begin{tabular}{|c|c|c|c|c|}
\hline Characteristic & Total & Sensor-augmented pump & Insulin pump alone & $p$ value \\
\hline No. of patients & 154 & 76 & 78 & \\
\hline Sex (male/female) & $80 / 74$ & $40 / 36$ & $40 / 38$ & 0.867 \\
\hline Age at onset (years) & $8.8 \pm 4.4$ & $8.5 \pm 4.6$ & $9.1 \pm 4.2$ & 0.381 \\
\hline $\mathrm{pH}$ at diagnosis & $7.30 \pm 0.13$ & $7.31 \pm 0.13$ & $7.29 \pm 0.14$ & 0.423 \\
\hline Base excess (mmol/l) & $-9.9 \pm 9.1$ & $-9.9 \pm 9.4$ & $-9.9 \pm 8.9$ & 0.983 \\
\hline Diabetic ketoacidosis, $n(\%)$ & $71(46.1)$ & $34(44.7)$ & $37(47.4)$ & 0.737 \\
\hline Fasting blood glucose (mmol/l) & $7.3 \pm 3.0$ & $7.3 \pm 3.2$ & $7.3 \pm 2.8$ & 0.939 \\
\hline Fasting C-peptide (nmol/l) & $0.16 \pm 0.10$ & $0.16 \pm 0.12$ & $0.15 \pm 0.08$ & 0.560 \\
\hline Age group 1 to 5 years & $0.10 \pm 0.08$ & $0.09 \pm 0.06$ & $0.11 \pm 0.09$ & 0.363 \\
\hline Age group 6 to 11 years & $0.16 \pm 0.09$ & $0.15 \pm 0.11$ & $0.16 \pm 0.08$ & 0.416 \\
\hline Age group 12 to 16 years & $0.22 \pm 0.10$ & $0.25 \pm 0.12$ & $0.19 \pm 0.07$ & 0.110 \\
\hline $\mathrm{HbA}_{1 \mathrm{c}}(\%)$ & $11.3 \pm 2.1$ & $11.2 \pm 2.1$ & $11.5 \pm 2.2$ & 0.472 \\
\hline Age group 1 to 5 years & $10.9 \pm 2.0$ & $11.2 \pm 2.0$ & $10.5 \pm 1.9$ & 0.233 \\
\hline Age group 6 to 11 years & $11.2 \pm 2.3$ & $10.7 \pm 2.3$ & $11.5 \pm 2.3$ & 0.161 \\
\hline Age group 12 to 16 years & $12.0 \pm 2.0$ & $11.8 \pm 1.9$ & $12.3 \pm 2.1$ & 0.412 \\
\hline Type 1 diabetes antibodies & $3.4 \pm 1.2$ & $3.4 \pm 1.3$ & $3.5 \pm 1.2$ & 0.511 \\
\hline ICA positive, $n(\%)$ & $140(90.9)$ & $66(86.8)$ & $74(94.9)$ & 0.083 \\
\hline GADA positive, $n(\%)$ & $113(73.4)$ & $56(73.7)$ & $57(73.1)$ & 0.932 \\
\hline IA-2A positive, $n(\%)$ & $115(74.7)$ & $55(72.4)$ & $60(76.9)$ & 0.516 \\
\hline IAA positive, $n(\%)$ & $64(41.6)$ & $31(40.8)$ & $33(42.3)$ & 0.848 \\
\hline ZnT8A positive, $n(\%)$ & $95(61.7)$ & $47(61.8)$ & $48(61.5)$ & 0.969 \\
\hline
\end{tabular}

Values are means \pm SD 
Table 3 Glycaemic outcomes during the study, according to age

\begin{tabular}{|c|c|c|c|}
\hline Variable & Sensor-augmented pump & Insulin pump alone & $p$ value \\
\hline Total cohort, $n$ & 76 & 78 & \\
\hline Average sensor use per week & $1.37 \pm 0.68$ & - & \\
\hline $\mathrm{HbA}_{1 \mathrm{c}}(\%)$ at baseline & $11.2 \pm 2.1$ & $11.5 \pm 2.2$ & 0.472 \\
\hline $\mathrm{HbA}_{1 \mathrm{c}}(\%)$ at 6 weeks & $7.6 \pm 0.9$ & $7.7 \pm 0.9$ & 0.561 \\
\hline $\mathrm{HbA}_{1 \mathrm{c}}(\%)$ at 26 weeks & $7.0 \pm 1.0$ & $7.2 \pm 1.2$ & 0.368 \\
\hline $\mathrm{HbA}_{1 \mathrm{c}}(\%)$ at 52 weeks & $7.4 \pm 1.2$ & $7.6 \pm 1.4$ & 0.451 \\
\hline Age group $1-5$ years, $n$ & 26 & 21 & \\
\hline Average sensor use per week & $1.51 \pm 0.82$ & - & \\
\hline $\mathrm{HbA}_{1 \mathrm{c}}(\%)$ at baseline & $11.2 \pm 2.0$ & $10.5 \pm 1.9$ & 0.233 \\
\hline $\mathrm{HbA}_{1 \mathrm{c}}(\%)$ at 6 weeks & $7.8 \pm 0.8$ & $7.7 \pm 1.0$ & 0.670 \\
\hline $\mathrm{HbA}_{1 \mathrm{c}}(\%)$ at 26 weeks & $7.1 \pm 0.7$ & $7.3 \pm 1.2$ & 0.314 \\
\hline $\mathrm{HbA}_{1 \mathrm{c}}(\%)$ at 52 weeks & $7.3 \pm 0.9$ & $7.6 \pm 1.0$ & 0.310 \\
\hline Age group 6-11 years, $n$ & 26 & 36 & \\
\hline Average sensor use per week & $1.37 \pm 0.59$ & - & \\
\hline $\mathrm{HbA}_{1 \mathrm{c}}(\%)$ at baseline & $10.7 \pm 2.3$ & $11.5 \pm 2.3$ & 0.161 \\
\hline $\mathrm{HbA}_{1 \mathrm{c}}(\%)$ at 6 weeks & $7.6 \pm 0.9$ & $7.6 \pm 0.8$ & 0.929 \\
\hline $\mathrm{HbA}_{1 \mathrm{c}}(\%)$ at 26 weeks & $6.9 \pm 1.0$ & $7.1 \pm 1.1$ & 0.382 \\
\hline $\mathrm{HbA}_{1 \mathrm{c}}(\%)$ at 52 weeks & $7.2 \pm 1.0$ & $7.4 \pm 1.2$ & 0.562 \\
\hline Age group $12-16$ years, $n$ & 24 & 21 & \\
\hline Average sensor use per week & $1.25 \pm 0.62$ & - & \\
\hline $\mathrm{HbA}_{1 \mathrm{c}}(\%)$ at baseline & $11.8 \pm 1.9$ & $12.3 \pm 2.1$ & 0.412 \\
\hline $\mathrm{HbA}_{1 \mathrm{c}}(\%)$ at 6 weeks & $7.5 \pm 1.0$ & $8.1 \pm 0.9$ & 0.073 \\
\hline $\mathrm{HbA}_{1 \mathrm{c}}(\%)$ at 26 weeks & $7.0 \pm 1.3$ & $7.0 \pm 1.3$ & 0.953 \\
\hline $\mathrm{HbA}_{1 \mathrm{c}}(\%)$ at 52 weeks & $7.7 \pm 1.6$ & $7.8 \pm 1.9$ & 0.847 \\
\hline
\end{tabular}

proportion of patients with an increase in fasting C-peptide concentration from baseline to 12 months was $39.2 \%$ (29 of 74 ) in the sensor-augmented pump group and $34.2 \%$ (26 of $76)$ in the control group $(p=0.528)$. Among patients with regular sensor use, C-peptide increase was seen in 17 of 37 patients $(45.9 \%)$. Significantly higher C-peptide concentrations were observed at 12 months in the sensor group (Table 4). There was a close to significant correlation between the frequency of sensor usage during the study and C-peptide concentrations at 12 months $(\rho=0.250$, $p=0.057)$. In the sensor-augmented pump group, more frequent sensor use during the first year was associated with a reduced decrease in fasting C-peptide at 12 months. Interestingly, more frequent sensor use at 26 weeks was also associated with lower C-peptide loss at 12 months as well $(\rho=0.323, p=0.008)$.
Table 4 Glycaemic variability, insulin requirements and C-peptide at 52 weeks

Values are means $\pm \mathrm{SD}$

\begin{tabular}{lcrr}
\hline Variable & $\begin{array}{l}\text { Sensor-augmented pump } \\
(n=76)\end{array}$ & $\begin{array}{l}\text { Insulin pump alone } \\
(n=78)\end{array}$ & $p$ value \\
\hline Glucose average (mmol/l) & $8.14 \pm 1.55$ & $8.15 \pm 1.75$ & 0.966 \\
Glucose SD (mmol/1) & $1.46 \pm 0.71$ & $1.76 \pm 1.05$ & 0.079 \\
MAGE (mmol/l) & $4.45 \pm 1.45$ & $5.11 \pm 1.87$ & 0.037 \\
Daily insulin dose (U/kg body weight) & $0.59 \pm 0.22$ & $0.64 \pm 0.23$ & 0.248 \\
Proportion of basal rate (\%) & $34.0 \pm 11.8$ & $29.7 \pm 10.4$ & 0.021 \\
Number of daily boluses & $7.9 \pm 3.6$ & $7.0 \pm 2.7$ & 0.097 \\
Fasting C-peptide (nmol/1) & $0.16 \pm 0.18$ & $0.12 \pm 0.11$ & 0.151 \\
C-peptide change from baseline (nmol/1) & $0.00 \pm 0.17$ & & $0.04 \pm 0.10$ \\
Fasting C-peptide (nmol/1) & & $0.04 \pm 0.04$ & 0.808 \\
Age group 1-5 years & $0.04 \pm 0.04$ & $0.12 \pm 0.10$ & 0.309 \\
Age group 6-11 years & $0.17 \pm 0.20$ & $0.18 \pm 0.13$ & 0.033 \\
Age group 12-16 years & $0.28 \pm 0.18$ & & \\
\hline
\end{tabular}




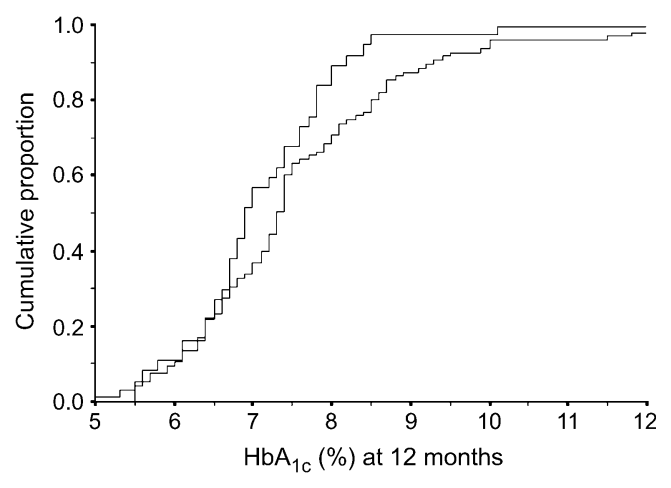

Fig. $1 \mathrm{HbA}_{1 \mathrm{c}}$ in patients with regular sensor use ( $\geq 1$ sensor/week; $n=37$; upper curve) and those in the combined group with no or low sensor use $(<1$ sensor/week; $n=95$; lower curve) compared by Kaplan-Meier plot and logrank test $(p=0.032)$

Severe hypoglycaemia and quality of life No episode of severe hypoglycaemia was reported in patients with a sensor-augmented insulin pump compared with four episodes in patients with insulin pump alone $(p=0.046)$. As assessed with the WHO-5 questionnaire, the dominant caregiver fulfilled on average the clinical diagnosis of depression (score below 48) at baseline (Table 5). The scores reached normal values at 6 months and remained normal after 1 year. The children's health-related quality of life showed significantly lower scores compared with

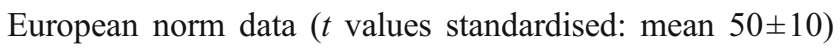
for physical, psychological, social support, and school at baseline, normalising after 6 months and remaining normal after 12 months with no difference between the intervention and control groups.

\section{Discussion}

This is the first study to examine the efficacy of implementing both CGM and continuous subcutaneous insulin infusion (CSII) in children and adolescents at the time of diagnosis of type 1 diabetes. The main results of this study can be summarised as follows: the primary outcome measure $\left(\mathrm{HbA}_{1 \mathrm{c}}\right.$ at 12 months) did not differ between the two treatment groups, fasting C-peptide and change in C-peptide in the total cohort were not significantly different and quality of life measures did not differ between the groups. Although we found that patients who were able to use CGM regularly had lower $\mathrm{HbA}_{1 \mathrm{c}}$ levels than those who did not, there were not enough of these patients to affect the overall results, indicating that the sensor systems are not yet effective enough or user-friendly enough for children and parents to have a clinically important impact on metabolic control during the first 12 months of the disease.

In our randomised, controlled trial, we observed beneficial effects of insulin pump therapy from the diagnosis of diabetes particularly in children with regular continuous sensor use. Although the $0.2 \%$ difference in $\mathrm{HbA}_{1 \mathrm{c}}$ values lacked statistical significance, the use of continuous glucose monitoring was associated with a better preservation of endogenous insulin secretion after 1 year of diabetes. Similar results with increasing C-peptide levels from baseline up to 2 years were also reported in a small cohort of patients treated with insulin pump and intensive subcutaneous insulin therapy from the IMDIAB Group [14]. It is well known that the loss of beta cell function tends to be slower in teenagers than in young children [15]. Therefore, one may speculate whether implementation of CGM from the onset of clinical disease may have an especially positive effect in the adolescent patient cohort independent of glycaemic control as seen in the present study. Moreover, imperfect adherence with long-term diabetes management has been recognised as a limitation to achieve good metabolic control in adolescents and young adults [15-17]. Taken together, the rapid introduction of continuous glucose monitoring into diabetes treatment may be helpful and effective from both metabolic and educational aspects. A stimulated C-peptide concentration may have been even more sensitive in detecting such effects of beta cell protection, but we refrained from using this measure because of the young age range included in this study. Nevertheless, the effects of sensor-augmented pump treatment starting from the clinical manifestation of type 1 diabetes have to be considered when immunological interventions aimed at the preservation of endogenous insulin secretion (such as anti-CD3-antibody treatment [18] or GAD vaccination [19]) are evaluated.

Compared with historical data, such as those recently reported by the Hvidøre Study Group in 275 children with multiple daily injections (mean $\mathrm{HbA}_{1 \mathrm{c}} 7.9 \pm 1.5 \%$ after 12 months of diabetes), we observed beneficial effects of insulin pump therapy during the first year of diabetes [15]. The overall $\mathrm{HbA}_{1 \mathrm{c}}$ was $7.5 \pm 1.1 \%$ and additional use of continuous glucose monitoring has no statistically significant impact on the overall glycaemic control, except in children with regular sensor use. In the latter group, average $\mathrm{HbA}_{1 \mathrm{c}}$ was $0.8 \%$ lower than in the Hvidøre report with more than half of these patients achieving $\mathrm{HbA}_{1 \mathrm{c}}$ below $7.0 \%$ without any severe hypoglycaemic event. Moreover, episodes of severe hypoglycaemia were not reported at all in patients with sensor-augmented pump treatment, but occurred in four patients in the control group. This difference has to be interpreted with caution because of the low frequency of severe hypoglycaemia in the whole study, particularly as previous studies have shown limited effectiveness of CGM as a preventive tool for hypoglycaemia [20,21].

Interestingly, in our study, patients with sensoraugmented insulin pump treatment had significantly lower glycaemic variability at 12 months of overt diabetes. Such 
Table 5 Psychosocial adaptation and quality of life

\begin{tabular}{|c|c|c|c|c|c|}
\hline Test & Group & Baseline & 6 months & 12 months & $p$ value $^{\mathrm{a}}$ \\
\hline \multirow[t]{3}{*}{ Mothers' wellbeing (WHO-5) } & Sensor-augmented pump & $49.3 \pm 23.9$ & $60.2 \pm 22.6$ & $62.7 \pm 18.9$ & $<0.001$ \\
\hline & Insulin pump alone & $44.7 \pm 21.6$ & $60.7 \pm 22.6$ & $60.8 \pm 19.3$ & $<0.001$ \\
\hline & $p$ value & 0.217 & 0.892 & 0.528 & \\
\hline \multirow{3}{*}{$\begin{array}{l}\text { KIDSCREEN-27: Physical wellbeing } \\
\text { (proxy/parents) }\end{array}$} & Sensor-augmented pump & $40.4 \pm 9.7$ & $49.4 \pm 9.0$ & $50.0 \pm 8.1$ & $<0.001$ \\
\hline & Insulin pump alone & $38.7 \pm 9.2$ & $46.8 \pm 8.8$ & $50.3 \pm 9.7$ & $<0.001$ \\
\hline & $p$ value & 0.418 & 0.114 & 0.879 & \\
\hline \multirow{3}{*}{$\begin{array}{l}\text { KIDSCREEN-27: Physical wellbeing } \\
\text { (children self-report) }\end{array}$} & Sensor-augmented pump & $43.7 \pm 9.4$ & $49.1 \pm 8.5$ & $51.2 \pm 8.8$ & $<0.001$ \\
\hline & Insulin pump alone & $39.8 \pm 8.2$ & $49.6 \pm 9.0$ & $49.9 \pm 8.2$ & $<0.001$ \\
\hline & $p$ value & 0.058 & 0.685 & 0.359 & \\
\hline \multirow{3}{*}{$\begin{array}{l}\text { KIDSCREEN-27: Psychological wellbeing } \\
\text { (proxy/parents) }\end{array}$} & Sensor-augmented pump & $40.3 \pm 10.5$ & $48.4 \pm 10.4$ & $47.8 \pm 9.3$ & $<0.001$ \\
\hline & Insulin pump alone & $40.4 \pm 10.9$ & $48.3 \pm 10.2$ & $48.6 \pm 10.3$ & $<0.001$ \\
\hline & $p$ value & 0.890 & 0.934 & 0.826 & \\
\hline \multirow{3}{*}{$\begin{array}{l}\text { KIDSCREEN-27: Psychological wellbeing } \\
\text { (children self-report) }\end{array}$} & Sensor-augmented pump & $45.0 \pm 10.6$ & $49.1 \pm 12.7$ & $50.4 \pm 9.2$ & 0.004 \\
\hline & Insulin pump alone & $44.4 \pm 11.0$ & $52.3 \pm 10.1$ & $50.3 \pm 10.8$ & 0.002 \\
\hline & $p$ value & 0.847 & 0.153 & 0.905 & \\
\hline \multirow{3}{*}{$\begin{array}{l}\text { KIDSCREEN-27: Autonomy and parents } \\
\text { (proxy/parents) }\end{array}$} & Sensor-augmented pump & $50.3 \pm 10.4$ & $51.4 \pm 11.2$ & $52.6 \pm 11.2$ & 0.844 \\
\hline & Insulin pump alone & $49.5 \pm 8.6$ & $50.4 \pm 8.9$ & $50.9 \pm 10.1$ & 0.646 \\
\hline & $p$ value & 0.594 & 0.570 & 0.206 & \\
\hline \multirow{3}{*}{$\begin{array}{l}\text { KIDSCREEN-27: Autonomy and parents } \\
\text { (children self-report) }\end{array}$} & Sensor-augmented pump & $51.1 \pm 8.5$ & $50.7 \pm 10.6$ & $52.5 \pm 10.0$ & 0.400 \\
\hline & Insulin pump alone & $48.8 \pm 9.6$ & $51.4 \pm 11.01$ & $50.2 \pm 9.9$ & 0.411 \\
\hline & $p$ value & 0.313 & 0.648 & 0.158 & \\
\hline \multirow{3}{*}{$\begin{array}{l}\text { KIDSCREEN-27: Social support and peers } \\
\text { (proxy/parents) }\end{array}$} & Sensor-augmented pump & $44.5 \pm 14.9$ & $50.3 \pm 9.9$ & $51.1 \pm 10.2$ & 0.007 \\
\hline & Insulin pump alone & $44.7 \pm 13.3$ & $50.7 \pm 10.4$ & $51.3 \pm 8.9$ & 0.004 \\
\hline & $p$ value & 0.998 & 0.826 & 0.860 & \\
\hline \multirow{3}{*}{$\begin{array}{l}\text { KIDSCREEN-27: Social support and peers } \\
\text { (children self-report) }\end{array}$} & Sensor-augmented pump & $47.1 \pm 11.0$ & $53.3 \pm 9.2$ & $52.4 \pm 9.6$ & 0.090 \\
\hline & Insulin pump alone & $44.2 \pm 10.7$ & $50.9 \pm 9.6$ & $50.8 \pm 9.0$ & 0.002 \\
\hline & $p$ value & 0.370 & 0.262 & 0.377 & \\
\hline \multirow{3}{*}{$\begin{array}{l}\text { KIDSCREEN-27: School environment } \\
\text { (proxy/parents) }\end{array}$} & Sensor-augmented pump & $45.8 \pm 14.0$ & $50.9 \pm 12.1$ & $51.4 \pm 10.1$ & 0.067 \\
\hline & Insulin pump alone & $47.1 \pm 11.6$ & $50.6 \pm 9.0$ & $50.9 \pm 9.2$ & 0.107 \\
\hline & $p$ value & 0.511 & 0.854 & 0.792 & \\
\hline \multirow{3}{*}{$\begin{array}{l}\text { KIDSCREEN-27: School environment } \\
\text { (children self-report) }\end{array}$} & Sensor-augmented pump & $47.4 \pm 11.7$ & $49.7 \pm 11.7$ & $52.8 \pm 9.8$ & 0.170 \\
\hline & Insulin pump alone & $45.4 \pm 10.1$ & $51.3 \pm 10.1$ & $51.3 \pm 10.2$ & 0.005 \\
\hline & $p$ value & 0.612 & 0.493 & 0.436 & \\
\hline
\end{tabular}

Values are mean $\pm \mathrm{SD}$

$p$ value for baseline data vs data at 12 months

reduction in variability has been observed previously in short-term interventions in children and adults [6]. Patients with CGM performed fewer finger pricks per day than those without CGM but it should be noted that CGM systems cannot eliminate the need for self monitoring blood glucose using an exogenous meter. Whereas insulin requirements were similar in both treatment groups, patients in the control group had a lower proportion of basal insulin accompanied by a lower number of daily boluses. This may be a consequence of the additional historical, current and predictive information from CGM allowing greater accuracy and application of treatment decisions. One may speculate that the use of CGM from the diagnosis of the disease allows patients to gain insight into their glycaemic homeostasis that may have a long-lasting educational effect and, therefore, may influence their long-term therapeutic handling of diabetes.

Although no differences were observed in the tests for quality of life and disease adjustment between the groups at any time points, the scores compared favourably with those from other studies [22]. Of particular note, a recent German study of parents' wellbeing assessed with the WHO-5 questionnaire from the onset up to 1 year of type 1 diabetes in 81 children ( $8.1 \pm 2.9$ years) with multiple injection therapy 
(K. Lange and T. Danne, unpublished data) showed a comparably low score at diagnosis $(48 \pm 28)$ with a significantly slower recovery after 6 months $(52 \pm 21, p<0.03)$ and still tending to be lower at 12 months $(58 \pm 20)$ than in either of the two CSII-based therapies in the present study. It may be that the greater flexibility of CSII alone may have allowed the rapid normalisation of psychosocial variables, which the questionnaires may not have been sensitive enough to detect between pumps and sensor-augmented pumps. However, there is no indication that the technical requirements of these modern therapies lead to a deterioration of health-related quality of life, as has been implicated repeatedly.

So far previous studies have shown that CGM can improve $\mathrm{HbA}_{1 \mathrm{c}}$ levels and enhance the management of type 1 diabetes in patients, particularly adults, motivated to use this technology. In a very recently published report of the STAR 3 Study Group, beneficial effects of sensoraugmented pump therapy compared with injection therapy have been clearly confirmed in a large cohort of adults with inadequately controlled type 1 diabetes as well as in children over 6 years of age [23]. As type 1 diabetes predominantly occurs in young patients with an increasing rate in the last decades [24], it is essential to achieve the best metabolic results in this relevant group of patients, taking into account that continuous use of CGM would increase insulin treatment costs by approximately $19 \%$ compared with CSII use alone. However, initial glycaemic achievements are closely related to long-term glycaemic control [25], whereas poor control early on may have consequences through a 'metabolic memory' despite improvements during the subsequent course of the disease [26]. It is important to note that the use of sensors declined progressively from the initial frequency of 2.1 sensors per week to 1.1 at 52 weeks in our study, indicating that CGM acceptance decreased over time and that repeated diabetes education for patients and parents is mandatory. Few physicians who treat children with type 1 diabetes would argue that the technology described in this paper makes it easier to achieve and maintain good glycaemic control in most patients. Any tool that improves the parent-patient knowledge is also valuable, but only if used effectively. The reason this study showed no difference between the groups may reflect the quality of education and care delivered to all of our patients and certainly the results in both groups are excellent, although data on preservation of beta cell function is less convincing.

The results of the present study indicate that children with type 1 diabetes can benefit from using a sensoraugmented insulin pump from the diagnosis of their disease, both in terms of achieving good glycaemic control and decreased glycaemic variability. According to more frequent sensor use and improved glycaemic control at week 52 , the younger age groups seem to profit mostly from sensor-augmented pump treatment in our study. However, the most important question is whether sensoraugmented pump therapy is universally better and whether it is cost effective for benefit gained. Another question is whether or not it is better to apply this therapy from diagnosis rather than moving through a slower, staged education and therapy process, especially given the Cpeptide results. Further work is needed to assess whether a decrease of glycaemic variability during the first year of clinical diabetes may have protective effects on beta cell function that are not reflected by the measurement of $\mathrm{HbA}_{1 \mathrm{c}}$.

Acknowledgements The Paediatric Onset Study Group recognises the efforts of the patients and their families and thanks them for their participation. Particular thanks go to the diabetes educators and nurses S. Bläsig, K. Remus (Walte), M. Haidl, L. Groele, S. Duble, M. Wierzchowska and A. Olszewska, to the local clinical investigators A. Szypowska, M. Błazik, T. Kracht, N. Datz, H. Bartelt and E. Schober for their important contribution to the study and N. Krug, E. Marquardt, B. Aschemeier, H. Gough and S. Liabat for their helpful contribution in organising the study. For a list of the participating investigators see the Electonic supplementary material (ESM).

Duality of interest This study is an investigator-initiated trial supported by Medtronic International Trading Sàrl, Tolochenaz, Switzerland. T. Danne received honoraria for scientific lectures, consulting fees and travel reimbursement from Medtronic, Abbott Diabetes Care, DexCom, Roche, Bayer HealthCare, E. Lilly, sanofiaventis and NovoNordisk. O. Kordonouri received honoraria for scientific lectures and travel reimbursement from Medtronic MiniMed and Bayer HealthCare, consulting fees and travel reimbursement from Lilly Deutschland and NovoNordisk. E. Pankowska has received honoraria for scientific lectures and consulting fees from Johnson \& Johnson, Roche Diagnostics, NovoNordisk. B. Rami received honoraria for scientific lectures or travel reimbursement from NovoNordisk, Medtronic MiniMed, sanofi-aventis and Bayer Health Care. T. Kapellen received honoraria for scientific lectures and travel reimbursement from Serono, Medtronic and Roche. K. Lange received honoraria for scientific lectures and travel reimbursement from Abbott Diabetes Care, Berlin Chemie, E. Lilly, Roche Diagnostics, sanofiaventis, NovoNordisk and Terumo.

\section{References}

1. Prince CT, Becker DJ, Costacou T, Miller RG, Orchard TJ (2007) Changes in glycaemic control and risk of coronary artery disease in type 1 diabetes mellitus: findings from the Pittsburgh Epidemiology of Diabetes Complications Study (EDC). Diabetologia 50:2280-2288

2. DCCT Group (1998) Effect of intensive therapy on residual betacell function in patients with type 1 diabetes in the diabetes control and complications trial. A randomized, controlled trial. Ann Intern Med 128:517-523

3. Ludvigsson J (2009) C-peptide an adequate endpoint in type 1 diabetes. Diabetes Metab Res Rev 25:691-693

4. Levin BS, Anderson BJ, Butler DA, Antisdel JE, Brackett J, Laffel LMB (2001) Predictors of glycaemic control and short-term adverse outcomes in youth and with type 1 diabetes. J Pediatr 139:197-203 
5. Deiss D, Bolinder J, Riveline J-P et al (2006) Improved glycemic control in poorly controlled patients with type 1 diabetes using realtime continuous glucose monitoring. Diab Care 29:2730-2732

6. Danne T, de Valk HW, Kracht T et al (2009) Reducing glycaemic variability in type 1 diabetes self-management with a continuous glucose monitoring system based on wired enzyme technology. Diabetologia 52:1496-1503

7. The Juvenile Diabetes Research Foundation Continuous Glucose Monitoring Study Group (2008) Continuous glucose monitoring and intensive treatment of type 1 diabetes. $\mathrm{N}$ Engl $\mathrm{J}$ Med 359:1464-1476

8. Service FJ, Molnar GD, Rosevear, Ackermann E, Gatweood LC, Taylor WF (1970) Mean amplitude of glycemic excursions, a measure of diabetic instability. Diabetes 19:644-655

9. Rewers M, Pihoker C, Donaghue K, Hanas R, Swift P, Klingensmith GJ (2009) ISPAD Clinical Practice Consensus Guidelines 2009. Assessment and monitoring of glycemic control in children and adolescents with diabetes. Pediatr Diab 10(suppl 12):71-81

10. The Disabkids Group Europe: The Disabkids questionnaires. Quality of life questionnaires for children with chronic conditions. Lengerich: Pabst Science Publishers

11. The KIDSCREEN Group Europe. The KIDSCREEN Questionnaires. Quality of life questionnaires for children and adolescents. Lengerich: Pabst Science Publishers

12. Rajmil L, Alonso J, Berra S, KIDSCREEN Group et al (2006) Use of a children questionnaire of health-related quality of life (KIDSCREEN) as a measure of needs for health care services. J Adolesc Health 38:511-518

13. World Health Organization, Regional Office for Europe (2008) Wellbeing measures in primary health care/the DEPCARE project: report on a WHO meeting, Stockholm, Sweden, 12-13 February 1998. WHO Regional Office for Europe, Copenhagen

14. Pozzilli P, Crino A, Schiaffini R, IMDIAB Group et al (2003) A 2-year pilot trial of continuous subcutaneous insulin infusion versus intensive insulin therapy in patients with newly diagnosed type 1 diabetes (IMDIAB 8). Diab Techn Therap 5:965-974

15. Mortensen HB, Swift PG, Holl RW, and Hvidoere Study Group on Childhood Diabetes et al (2009) Multinational study in children and adolescents with newly diagnosed type 1 diabetes: association of age, ketoacidosis, HLA status, and autoantibodies on residual beta-cell function and glycemic control 12 months after diagnosis. Pediatr Diabetes 11:218-226

16. Wysocki T, Iannoti R, Weissberg-Benchell J, Family Management of Childhood Diabetes Steering Committee et al (2008) Diabetes problem solving by youths with type 1 diabetes and their caregivers: measurement, validation, and longitudinal associations with glycemic control. J Pediatr Psychol 33:875-884

17. Insabella G, Grey M, Knafl G, Tamborlane W (2007) The transition to young adulthood in youth with type 1 diabetes on intensive treatment. Pediatr Diabetes 8:228-234

18. Keymeulen B, Vandemeulebroucke E, Ziegler AG et al (2005) Insulin needs after $\mathrm{CD} 3$-antibody therapy in new-onset type 1 diabetes. N Engl J Med 352:2598-2608

19. Ludvigsson J, Faresjö M, Hjorth M et al (2008) GAD treatment and insulin secretion in recent-onset type 1 diabetes. $\mathrm{N}$ Engl $\mathrm{J}$ Med 359:1909-1920

20. The Juvenile Diabetes Research Foundation Continuous Glucose Monitoring Study Group (2009) Factors predictive of use and of benefit from continuous glucose monitoring in type 1 diabetes. Diab Care 32:1947-1953

21. Hermanides J, DeVries JH (2010) Sense and nonsense in sensors. Diabetologia 53:593-596

22. Bullinger M, Schmidt S, Petersen C (2002) Assessing quality of life of children with chronic health conditions and disabilities: a European approach. Int J Rehabil Res 25:197-206

23. Bergenstal RM, Tamborlane WV, Ahmann A et al (2010) Effectiveness of sensor-augmented insulin-pump therapy in type 1 diabetes. N Engl J Med 363:311-320

24. Patterson CC, Dahlquist GG, Gyürüs E, Green A, Soltész G, EURODIAB Study Group (2009) Incidence trends for childhood type 1 diabetes in Europe during 1989-2003 and predicted new cases 2005-20: a multicentre prospective registration study. Lancet 373:2027-2033

25. Danne T, Mortensen HB, Hougaard P, Hvidøre Study Group on Childhood Diabetes et al (2001) Persistent differences among centres over 3 years in glycemic control and hypoglycemia in a study of 3,805 children and adolescents with type 1 diabetes from the Hvidøre Study Group. Diab Care 24:1342-1347

26. White NH, Sun W, Cleary PA et al (2008) Prolonged effect of intensive therapy on the risk of retinopathy complications in patients with type 1 diabetes mellitus: 10 years after the Diabetes Control and Complications Trial. Arch Ophthalmol 126:1707-1715 